\title{
MARCUSCHI, UM LETREIRO VIVO
}

\section{MARCUSCHI, LIVE SIGNBOARD}

\begin{abstract}
Angela Paiva Dionisio*
Resumo: Luiz Antônio Marcuschi, um dos mais influentes linguista brasileiro, foi o homenageado na XXVI Jornada do Grupo de Estudos Linguísticos do Nordeste (GELNE), realizada em Recife, Pernambuco, em 2016. Originalmente, este texto foi produzido a convite da diretoria do GELNE, à época, para compor a mesa de abertura do referido evento. Dentre as possibilidades discursivas, optou-se por uma linha de construção textual que consistiu em associar o conceito de Letreiro Vivo, oriundo da literatura espírita, às ideias e ao agir de Marcuschi. Destacam-se, neste texto, o professor, o pesquisador, o amigo, o irmão, o orientador, o mestre, ou seja, alguns dos roteiros humanos que Marcuschi representou no espaço acadêmico.
\end{abstract}

Palavras-Chave: Luiz Antônio Marcuschi; GELNE; letreiro vivo

Abstract: Luiz Antônio Marcuschi, one of the most influential Brazilian linguists, was honored during the XXVI Jornada do Grupo de Estudos Linguísticos do Nordeste (GELNE), which took place in Recife, Pernambuco in 2016. At the invitation of GELNE this text was produced originally for participation in the opening ceremonies of the referred event. Among the discursive possibilities, a textual construction was chosen that consisted of associating the concept of Live signboard from the literature of Spiritism, with the thoughts and actions of Marcuschi. Prominence in this text is given to the professor, the friend, the brother, the mentor, the Mestre, some of the human scripts that Marcuschi represented in the academic world.

Keywords: Luiz Antônio Marcuschi; GELNE, Live Signboard

1. Saudação

Prezados participantes da XXVI Jornada do GELNE, Prezados colegas, Senhoras e Senhores,

Em A propósito da metáfora, Marchuschi inicia seu texto exatamente assim:

Seria possível acrescentar algo de interesse à quase ininterrupta investigação da metáfora desde que Aristóteles a definiu em sua Poética? Como efeito, poucos temas experimentam uma tradição teórica tão unitária e fiel como a metáfora. Parece, portanto,

\footnotetext{
* Professora visitante no PPGLE da UFCG; é professora titular aposentada da Universidade Federal de Pernambuco. Coordenou a área do PIBID Letras/Português UFPE, juntamente com Suzana Cortez (2014-2016). Atuou como professora e orientadora no PROFLetras UFPE (2013-2015). Possui graduação em Licenciatura Plena em Letras pela Universidade Federal de Campina Grande (1986), mestrado (1992) e doutorado em Linguísitica (1998) pela Universidade Federal de Pernambuco.
} 
perfeitamente, plausível retomar a problemática, se não para trazer novidades, pelo menos para renovar o debate com colocações ainda pouco exploradas. (MARCUSCHI, 2007, p. 119)

Foi assim também que me senti por muito tempo: seria possível acrescentar algo de interessante a conhecidíssima história de Luiz Antônio Marcuschi? Seria possível investigar os temas abordados por ele e sintetizá-los neste espaço de tempo? Um fato dei como ponto de partida: jamais teria competência, sem falsa modéstia, para tecer a trajetória teórica de Marcuschi.

Permiti-me, então, mais uma vez, assim como tento fazer por anos, desde que comecei a ser sua aluna, imitar os passos de Marcuschi. Como sabia que, provavelmente, não traria novidades sobre o linguista, o professor, o pesquisador, o estudioso, o mestre Marcuschi, tentei inovar na forma de abordar o nosso homenageado. Busquei atrelar um texto da literatura espírita para as minhas reflexões. Trata-se do texto Letreiros Vivos, de André Luiz, psicografia de Waldo Vieira, publicado no livro $O$ Espírito da Verdade, pela Federação Espírita Brasileira, em 1961. ${ }^{1}$

\footnotetext{
${ }^{1}$ À época da escrita do texto, 2016, senti-me um pouco preocupada com a inserção da literatura religiosa na construção da argumentação. Hoje, 2019, ao ler, A palavra de Deus na palavra humana, de Benedito Gomes Bezerra, publicado pela Pá de Palavra, talvez eu tivesse me encorajado mais e me intimidado menos.
} 
Primeiramente $^{2}$, retomo do discurso proferido por Ingedore Koch em dezembro de 2006, quando da homenagem aos professores fundadores do Programa de Pós-Graduação em Letras da UFPE, a informação de que em 1983, no IV Congresso de Língua Portuguesa PUC/SP, Marcuschi ministrou a conferência plenária do dia, intitulada "Linguística do Texto: o que é e como se faz". A linguista da Unicamp, citando um trecho da música Sampa, "Alguma coisa acontece no meu coração...", continua a narração dizendo que "à tarde, cruzamo-nos no corredor, entramos numa sala de aula vazia e começamos a conversar. Imediatamente, percebemos a enorme afinidade existente entre nós e que faria de nós mais do que amigos: irmãos!” (KOCH, 2000, p.35).

A partir de agora começo a minha tentativa de associação entre as ideias que justificam o título dado a minha fala: Marcuschi, um letreiro vivo. O depoimento de Ingedore Koch me remete ao conceito de suporte textual, apontador por Marcuschi. Para o autor, "a ideia central é que o suporte não é neutro e o gênero não fica indiferente a ele. (...) Ele é imprescindível para que o circule na sociedade e deve ter alguma influência na natureza do gênero." (MARCUSCHI, 2008, p. 174). Não estou reduzindo Marcuschi a um mero suporte textual, por favor, não me entendam assim.

Estou buscando dizer que Ingedore Koch percebeu o LETREIRO VIVO MARCUSCHI. E por quê? Porque é justamente "nas faixas mínimas de sua experiência cotidiana, (que) surge o roteiro humano que você representa para os outros" (LUIZ, 2008, p. 251). Para Koch, o roteiro humano que Marcuschi representou foi o de um amigo, de um irmão! Cada um de nós, neste auditório, que conviveu com Marcuschi, pode nomear o roteiro humano que ele representou para si. Quiçá, alguns possamos nomear mais de um roteiro humano!

Outra característica do letreiro vivo reside no fato de se poder "visualizar os tecidos que envolvem o corpo configurando-lhe o senso de naturalidade." O que é naturalidade? Uma definição possível para o contexto marcushiano seria "propriedade de vontade do sujeito que elegeu para si mesmo". Disponibilidade e naturalidade se fundem no agir de Marcuschi, pois para ele "não existe um uso significativo da língua fora das inter-relações pessoais e sociais situadas.” (MARCUSHI, 2008, p.23).

E é, do espaço do Centro de Artes e Comunicação da UFPE, por onde caminhou desde 1976, que busquei trazer uma cena para traduzir o senso de naturalidade, simplicidade e paixão. Na hora do almoço, é abordado por alunos da $8^{a}$ série do Colégio de Aplicação, atual $9^{\circ}$ ano, que faziam uma pesquisa sobre questões gramaticais. Os jovens pesquisadores, no início do vídeo, mostraram algumas pessoas se recusando a participar da pesquisa. Recortei apenas o trecho do diálogo deles com Marcuschi.

Observamos na cena a reação de entusiasmo ao encontrarem um professor, participando de sua entrevista. Surpresa e satisfação manifestaram os alunos, ao perceberem a análise que Marcuschi fazia das questões de pesquisa que lhe foram apresentadas, pois todas as alternativas eram comentadas, assim como a elaboração dos enunciados das questões! Num determinado momento, os jovens queriam dar por encerrada a entrevista, parecendo meio assustados com a quantidade de informação que estavam recebendo e com e a possível perda do controle da entrevista. Num determinado momento, relaxaram e só se divertiam. Foram indagados sobre o que queriam perguntar na questão que envolvia a partícula "ou": "Dependem do que vocês querem, diz Marcuschi, pois o "ou" pode inclusivo ou exclusivo. Demonstrando

\footnotetext{
${ }^{2}$ Primeiramente, termo que, à época, sinalizava discursivamente a postura de quem se posicionava contra o governo do presidente Temer; era parte da expressão "Primeiramente, fora Temer".
} 
surpresa, um dos jovens, sorrindo, responde "qualquer coisa". Era necessário responder apenas a duas questões, Marcuschi respondeu a todas. E mais, fez reflexões indo além do caráter normativo da língua. Eis o link para a cena:

Figura 4: Marcuschi responde a entrevista de alunos do ensino básico.mp4

Não importava para Marcuschi quem eram seus interlocutores, quem eram seus alunos! Não havia distinção se eram da graduação, do mestrado, do doutorado ou do ensino básico. A simplicidade em lidar com o conhecimento e a disponibilidade em compartilhar este saber foram aulas ministradas continuamente em qualquer situação, em qualquer contexto. Naturalidade, simplicidade e paixão formavam uma tríade indissociável. Não é sem razão que era chamado de "mestre". Para o Mestre,

“é importante ter em mente que o ensino de língua na escola não é formar linguistas e muito menos analistas da fala, analistas do texto ou da conversação. Tudo se resume a este objetivo: ensinar os alunos a perceberem a riqueza que envolve o uso efetivo da língua como um patrimônio maior do qual não podemos abrir mão. Pois, se há um estudo que vale a pena no ensino básico é o estudo da língua e suas possibilidades." (MARCUSCHI, 2001, p.30)

Este é Marcuschi: disponível para todos. Comportamento reconhecido pelos seus pares, conforme nos narra Koch no discurso já mencionado:

De particular relevância foi sua atuação no Projeto de Gramática do Português Falado, que teve como coordenador-geral Ataliba Teixeira de Castilho. No subgrupo que me coube coordenar, o de Organização textual-interativa, desempenhou o papel mais importante: éramos todos ainda leigos em matéria de língua falada e, quando nos deparamos com o material sobre o qual deveríamos nos debruçar, constituído de inquéritos do Projeto NURC/BRASIL, sentimo-nos bastante confusos, sem saber como fazer e que rumo tomar, pois toda a nossa prática consistia no estudo da língua escrita. Pois bem, Marcuschi chegava à PUC/SP, local de nossas reuniões de pesquisa, com uma pasta enorme, cheia de material selecionado, que avidamente reproduzíamos e passávamos a discutir. Dessa forma, fomos aos poucos nos familiarizando com as questões próprias da oralidade e conseguimos, sempre sob a sua orientação, construir os pilares teóricos básicos e as categorias de que necessitávamos para nossa pesquisa. Na verdade, deveria ter sido ele o coordenador e não eu. Mas, quando lhe propusemos isso, no primeiro encontro do PGPF, realizado em Águas de São Pedro, modestamente — como é de seu 
costume - recusou, argumentando com a distância e consequente maior dificuldade de contatos urgentes, e insistiu que fosse eu a coordenar os trabalhos da equipe. (KOCH, 2006, p.39)

A pasta enorme cheia de material que era de seu uso pessoal, mas que ia para São Paulo para todos do grupo! Este comportamento era rotineiro: as primeiras versões de seus textos eram distribuídos entre alunos, eram entregues após as inúmeras conferências país a fora. Muitas vezes, quando um artigo era publicado, todo mundo já tinha a cópia! Ou seja, "os seus objetos de uso pessoal compõem o edifício de sua simplicidade". (LUIZ, 2008, p. 251).

Para quem não estudou com Marcuschi deixe-me dar uma pequena noção de como "a ordem de seus afazeres indica-lhe o grau de disciplina" (LUIZ, 2008, p. 251). Um plano de curso chegava a ter 15 páginas! É o caso, por exemplo, da disciplina Gêneros Textuais: conceituação, constituição e circulação, ministrado no segundo semestre de 2004, no Programa de Pós-Graduação em Letras da UFPE. Quando mencionava os objetivos do programa, o fazia de forma argumentativa. Trago apenas os dois primeiros parágrafos do plano de curso para ilustrar:

NESTE Curso serão vistas algumas teorias sobre os gêneros textuais com base nos trabalhos mais recentes sobre o tema. Isto significa que o Curso é de caráter sistemático e não histórico. A tese central é a de que os gêneros textuais são uma espécie de gramática sóciodiscursiva, isto é, eles são parte da organização social e se dão como prática discursivas poderosas na vida diária. Assim, com base em Carolyn Miller (1984), tratamos os gêneros textuais como eventos comunicativos e "formas de ação social", operando como parte integrante da sociedade. A partir desta posição, identificam-se aspectos relativos à sua circulação, conceituação, descrição e análise. Embora não sejam hoje prioritárias, algumas questões relativas à classificação também serão tratadas. Deve-se frisar, no entanto, que a ênfase não está na classificação nem na tipologia. Hoje já se admite que uma classificação sistemática dos gêneros constitui missão relativamente impossível, tendo em vista sua multiplicidade e sua característica de hibridização (mesclas) e imbricamento (encaixes). Ideias a este respeito podem ser vistas em Dominique Maingueneau (2004). Assim, o foco no estudo dos gêneros desloca-se das tipologias para a análise dos componentes social, histórico e cognitivo dos gêneros textuais, bem como sua inserção institucional e seu funcionamento nas comunidades discursivas.

Também será desenvolvida uma distinção proveitosa entre gênero textual, enquanto materialização e exteriorização do texto em algum contexto social e histórico, em grande número de realizações, e tipo textual, enquanto uma entidade abstratamente definida como uma modalidade retórica (sequência, no sentido de Adam) de formato linguístico típico, em número limitado de realizações e que não chega a caracterizar um gênero. Nem todos os gêneros se dão homogeneamente em relação aos tipos. Pois em geral um texto não apresenta apenas uma sequência e isto leva a uma diversidade de modos retóricos (modalidades de sequenciação tipológica). Assim, um gênero pode realizar uma série de tipos ou modalidades retóricas. De um modo geral, por serem limitados quanto ao número e representarem sequências mais ou menos estereotipadas quanto aos aspectos linguísticos, os tipos textuais não têm uma relação direta nem 
significativa com os contextos sociais em que se realizam. O contrário ocorre com os gêneros textuais e por isso mesmo são muito mais difíceis de serem descritos. Duvida-se da possibilidade de identificar uma "super-estrutura" para cada gênero. Por isso, discute-se menos sua forma e mais suas funções e formas de ação. Esta questão será central neste Curso, tendo em vista que nos dedicaremos em especial às questões funcionais e muito menos aos problemas formais em relação aos gêneros.

Se a sua pasta enorme era cheia de material selecionado para seus colegas professores, suas aulas escritas para os seus alunos. Exatamente. Marcuschi escrevia as aulas e entregava aos alunos da PPGLE da UFPE. Por exemplo, neste curso que mencionei sobre Gêneros Textuais, o tema da AULA 07 era Mikhail Bakhtin: a perspectiva sócio-histórica na teoria dos gêneros do discurso. Aos alunos foram entregues 17 páginas escritas sobre o tema! Detalhe: o material não era entregue no dia da aula nem na semana anterior; as sínteses (17 páginas, por exemplo, para apenas uma aula) de todas as aulas do semestre eram dadas aos participantes no primeiro dia de aula! O que quero dizer com tudo isto? Além do já mencionado aspecto de que seus objetos de uso pessoal, no caso de Marcuschi, seus livros, suas ideias, "compõem o edifício de sua simplicidade" (LUIZ, 2008, p. 251). Nestes episódios visualizamos mais um aspecto que compõe a noção de letreiro vivo, que são: "o cumprimento das suas obrigações denuncia-lhe o valor da palavra empenhada" (LUIZ, 2008, p. 251).

Retomemos a entrevista com os alunos do ensino básico, o momento da despedida: "Saudações, Divirtam-se muito!" Quantas vezes ouvimos tais expressões ao final de uma aula, de uma orientação, de uma conversa rápida no corredor ou na sala do cafezinho do Departamento de Letras, após uma dúvida esclarecida no corredor ou uma indicação de leitura ao final de uma palestra? Ou simplesmente, ao final do dia! "Divirtam-se muito!" ecoava traduzindo a firmeza dos seus ideais. Eis aqui mais um traço do "letreiro vivo". A segurança da sua opinião traduz a firmeza dos seus ideais. Impossível não sair confiante, após uma conversa com Marcuschi.

Peço licença agora para ousar representar cada um de vocês que conviveram com Marcuschi e queria muito que ele pudesse me ouvir, pois vou repetir, literalmente, André Luiz (2008, p. 252): "o seu presente diz, para todos, o que você foi no passado e o que você será no porvir, com reduzidas possibilidades de erro." Era assim que nos sentíamos após uma boa conversa com Marcuschi, uma boa leitura de um texto de Marcuschi ou de aula ou palestra com Marcuschi. Presente e passado se fundem em memórias, em artigos e livros publicados, em teses e dissertações orientadas, em vídeos que preservam sua voz, seus gestos, sua alegria.

A sua alegria não se reduzia a expressões verbais. Antes de Marcuschi chegar, chegava o "sorriso de Marcuschi”! Não podia ser diferente, uma vez que para ele, "toda atividade discursiva e todas as práticas linguísticas se dão em textos orais ou escritos com a presença de semiologias de outras áreas, como a gestualidade e o olhar, na fala, ou elementos pictóricos e gráficos, na escrita" (MARCUSCHI, 2005, p. 13). Para quem entendia texto como "um sistema de conexões entre elementos, construído numa orientação de multissistemas," que envolve aspectos linguísticos e não linguísticos no seu processamento, tornando-se em geral multimodal (MARCUSCHI, 2008, 80), o sorriso não se ausentava neste processamento textual. Sorrisos revelam "os traços do semblante (que lhe) pintam o clima interior" (ANDRÉ, 2008, p. 251): sempre disponível, sempre entusiasmado com fazer linguístico.

Gostaria de mencionar um encontro de sorrisos. Os sorrisos de Charles Bazerman e Luiz Antônio Marcuschi. Quis os deuses das teorias dos gêneros textuais 
que eu pudesse favorecer a este encontro. Fui realizar o meu estágio de pósdoutoramento com o Prof. Bazerman por influência das aulas de Marcuschi. Ao término do estágio, com a cara e a coragem, convidei Bazerman para vir ao Brasil (sem passagem nem hospedagem). Ele aceitou imediatamente.

Bazerman desejava muito conhecer Marcuschi e lamentava muito não ler português para ter acesso aos textos de Marcuschi. Apresentei os dois em Brasília por ocasião da Abralin, mas foi aqui em Recife, por ocasião do evento Gênero Textual e Práticas Sociais: um encontro com Charles Bazerman, em março de 2005, que os dois conversaram e muito sobre suas ideias sobre gênero, linguagem e tudo mais.

Foi em um dos jantares que pudemos vivenciar questões como "o que é mesmo ter uma língua em comum?” (MARCUSCHI, 2007, p.113). Começaram com o auxílio de Judith Hoffnagel como tradutora, mas entre eles, o mais importante "para interagir (...) tinham muito em comum". Inglês, espanhol, alemão, português, gestos, desenhos em guardanapos e assim foram discutindo seus pontos de vista, suas teorias, até delimitarem suas fronteiras argumentativas com gestos com as mãos até o meio da mesa. Chegaram ao meio da mesa, ao mesmo tempo, num empate de concordância que foi selado com um grande aperto de mãos e uma gargalhada, enquanto nós éramos mera audiência; éramos sim uma privilegiada audiência. Felizmente, pude fazer esta foto que apesar de qualidade não muito boa, se tornou histórica.

Bazerman e Marcuschi jogaram fantasticamente o jogo dos atos de linguagem. E mais, ambos se manifestaram como letreiros vivos, visto que vivenciaram reciprocamente a máxima: "o teor da amizade dos seus vizinhos para com a sua pessoa, qualifica a sua capacidade de se fazer entendido" (ANDRÉ, 2008, p. 251). Lembremos de que para ambos, "dominar gêneros é agir politicamente" (MARCUSCHI, 2005, p. 12.

Figura 6: Marcuschi e Bazerman: sintonia em ideias, afinidades além das teorias 
Gostaria de destacar mais uma virtude de um letreiro vivo: "o diapasão da sua palestra dá o tom da sua altura íntima" (ANDRÉ, 2008, p. 251). Olha só como me arrisco! Mas não é apenas a Marcuschi a quem me refiro e sim aos seus leitores. E por que aos seus leitores? Porque se desejamos ser designers das ideias de Marcuschi, precisamos ficar atentos para o fato de que "a uniformidade entre o movimento das suas ideias, dos seus conceitos e das ações disseca, à vista de todos, a fibra de sua vontade." (LUIZ, 2008, p. 252).

Deixem-me explicar. Umberto Eco (2010, p.17), ao refletir sobre a possibilidade do desaparecimento ou não do livro com o surgimento da internet, afirma que

o livro é como a colher, o martelo, a roda ou a tesoura. Uma vez inventados, não podem ser aprimorados. Você não pode fazer uma colher melhor. Designers tentaram melhorar, por exemplo, o sacarolhas, com sucessos modestos, e, por sinal, a maioria nem funciona direito. (...) Talvez ele evolua em seus componentes, talvez as páginas não sejam mais de papel. Mas ele permanecerá o que é.

Assim é Marcuschi, ele permanecerá o que é. Não estou dizendo que as ideias de Marcuschi não podem ser aprimoradas, desenvolvidas, ampliadas. E se eu pensasse diferente, estaria demonstrando que nada teria aprendido com o Mestre. Quero ressaltar que para sermos designers das ideias de Marcuschi precisamos ter a responsabilidade não apenas em pontuar conceitos de texto, tipo de texto, gênero textual, referenciação, língua, linguagem, cognição, discurso, coerência, compreensão, entre outros, isoladamente. Precisamos atentar, por exemplo, para a multiplicidade de disciplinas nas quais ele discutia estes conceitos. Só para mencionar as disciplinas ministradas no PG Letras da UFPE, Marcuschi "passeavam" pela sociolinguística, filosofia da linguagem, linguística de texto, psicologia da linguagem, semântica, pragmática, lógica simbólica, linguística cognitiva, análise da conversação, análise de gêneros textuais, análises da língua falada e língua escrita.

Em outras palavras, o movimento das suas ideias, dos seus conceitos e das ações revelava a vontade de fazer, de construir. Qual área dos estudos da linguagem pode dizer que não foi impactada pelas ideias de Marcuschi? Quantos projetos de pesquisa estão "adormecidos" nos textos de Marcuschi? Quantas perguntas de pesquisa estão por lá? Com quais lentes temos lido e devemos ler Marcuschi através dos tempos? Tempo, tempo, tempo...

Homenagear Marcuschi só se faz agindo, construindo! Palavras paradas não o representam. O diapasão das suas palestras, das suas aulas trazia o tom do tom do fazer com saber, simplicidade e paixão! Esta melodia pode ser ouvida na leitura dos seus textos, mas dependerá também da fibra da nossa vontade. Parafreseando Lispector, Marcuschi jamais se deixaria prender por um gênero textual acadêmico ou literário. Marcuschi são ideias; ideias possuem vida; vida é renovação. Logo, ideias não morrem.

Uma vez Marcuschi disse em uma entrevista: "Uma criança quando faz uma redação ela pode pôr lá o nome da professora e dizer "gosto muito de você", mas ela pode desenhar um coração e botar o nome dentro do coração e parece que gosta muito mais." Veja o link para o vídeo 


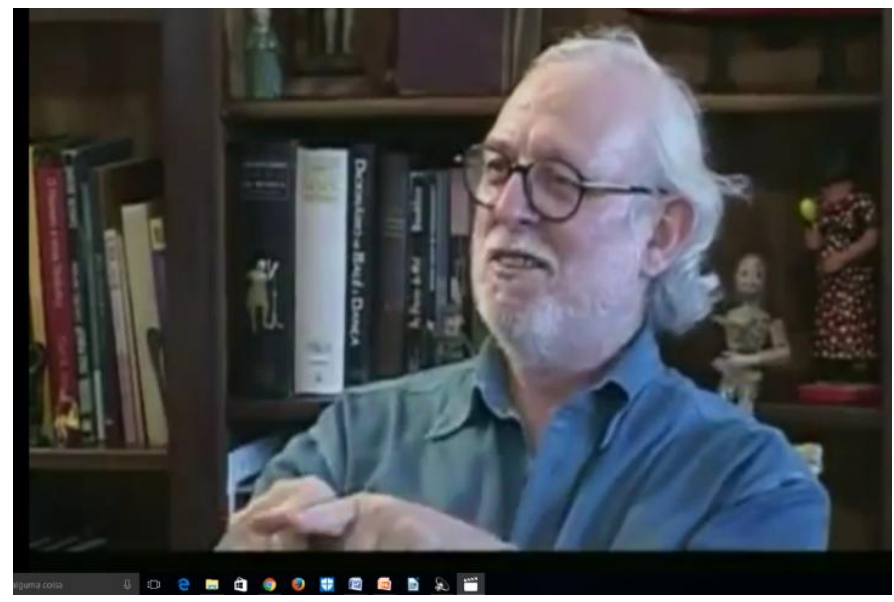

Figura 7: Trecho do vídeo Fala e Escrita

Pois é Marcuschi, não desenhei um coração com o seu nome dentro, mas mantendo a tentativa de seguir você, que 1975, afirmava que "a metáfora não se esgota, pois nos limites da linguagem nem no âmbito das relações lógicas", resolvi plantar o seu nome em todos os estados do nosso país para dizer haverá sempre uma farta colheita da safra de ideias, de postura ética, de companheirismo, de fibras de vontade e de entusiasmo pelo agir científico e pelo agir docente que brotaram das leituras e audiências de seus textos. Toda a plantação será adubada pelas memórias contadas pelos amigos vizinhos, pois em cada partezinha deste território brasileiro (e em terras além das nossas fronteiras) você continuará sempre presente. Presente em nossos corações e em nossas pesquisas. Mas afinal, o que estou eu a dizer? É, você, Marcuschi quem continuará produzindo a energia que pode nos iluminará. Tu és o LETREIRO VIVO.

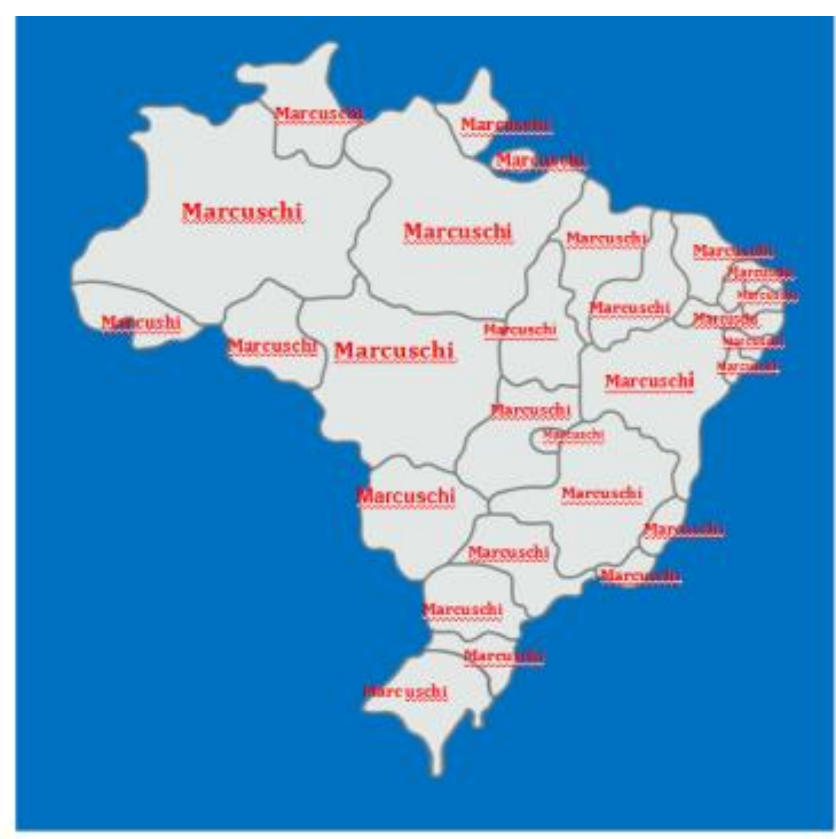

Muito obrigada! 


\section{Referência}

ANDRÉ, L. Letreiros Vivos. In: O Espírito da Verdade: estudos e dissertações em torno do Evangelho segundo o Espiritismo, de Allan Kardec, por vários Espíritos, psicografado por Francisco Cândido Xavier e Waldo Vieira. Rio de Janeiro: FEB, 2008.

BEZERRA, Benedito. A palavra de Deus na palavra humana. São Paulo: Pá de Palavra, 2019.

KOCH, I. Luiz Antônio Marcuschi. In: DIONISIO, A. VIEIRA, A. T. \& FALCONE, K. (ORG.) O Caminho se faz Caminhando: 30 ANOS do PPGLETRAS da UFPE. Recife: EDUFPE, 2006

MARCUSCHI, Luiz. Antônio. Apresentação. In BAZERMAN, Charles. Gêneros Textuais, Tipificação e Interação. São Paulo: Cortez, 2005.

MARCUSCHI, Luiz Antônio. Produção textual, análise de gêneros e compreensão. São Paulo: Parábola, 2008.

MARCUSCHI, Luiz Antônio. Fenômenos da Linguagem. Rio de Janeiro: Lucerna, 2007.

\section{ANEXO \\ LETREIROS VIVOS \\ ANDRÉ LUIZ \\ Psicografada por WALDO VIEIRA Sobre o Item 3 do Cap. XVII do ESE}

Nas faixas mínimas da sua experiência cotidiana surge o roteiro humano que você representa para os outros.

Os traços dos semblantes pintam-lhe o clima interior

Os seus objetos de uso pessoal compõem o edifício da sua simplicidade.

A ordem dos seus afazeres indica-lhe o grau de disciplina.

O cumprimento das suas obrigações denuncia-lhe o valor da palavra empenhada.

O teor da amizade de seus vizinhos, para com a sua pessoa, qualifica a sua capacidade de se fazer entendido.

O diapasão da sua palestra dá o tom da sua altura intima.

A segurança da sua opinião traduz a firmeza dos seus ideais.

Os tecidos que lhe envolvem o corpo configuram-lhe o senso de naturalidade

As iguarias da sua mesa revelam-lhe o papel do estômago no mundo moral

A natureza do cuidado com o seu físico fala francamente de suas possíveis relações com a vaidade.

O seu presente diz, para todos, o que você foi no passado e o que você será no porvir, com reduzidas possibilidades de erro.

A uniformidade entre o movimento das suas idéias, dos seus conceitos e das suas ações disseca, à vista de todos, a fibra da sua vontade

Todas as criaturas que lhe partilham a existência lêem incessantemente os letreiros vivos que lhe estabelecem a verdadeira identidade nos panoramas da Vida, respondendo-lhe as mensagens inarticuladas com aversão ou simpatia, contentamento ou desagrado, conforme a sua plantação de bem ou mal. 